\title{
NEW TYPE OF STRONGER FORM OF IG CLOSED SETS
}

\author{
A. Thiripuram \\ Department of Mathematics \\ Jeppiaar Engineering College \\ Chennai, Tamil Nadu, INDIA
}

\begin{abstract}
An ideal on a set $\mathrm{X}$ is a non empty collection of subsets of $\mathrm{X}$ with heredity property which is also closed under finite unions. In this paper, we have introduced stronger forms of g-closed sets via ideal topological space. Also we have studied the properties of the stronger forms of g-closed sets with respect to an ideal.
\end{abstract}

AMS Subject Classification: $54 \mathrm{C} 10$

Key Words: Topological spaces, generalized closed set, strongly generalized closed set and Ideal.

\section{Introduction}

Nowadays ideals are playing very important role in General Topology. It was the works of Newcomb[10], Rancin[13], Samuels[14] and Hamlet and Jankovic $([2,3,4,5,6])$ which motivated the research in applying topological ideals to generalize the most basic properties in General Topology. A nonempty collection I of subsets on a topological space $(\mathrm{X}, \tau)$ is called a topological ideal if it satisfies the following two conditions:

(i) If $\mathrm{A} \in \mathrm{I}$ and $\mathrm{B} \subset \mathrm{A}$ implies $\mathrm{B} \in \mathrm{I}$.(heredity).

(ii) If $\mathrm{A} \in \mathrm{I}$ and $\mathrm{B} \in \mathrm{I}$ then $\mathrm{A} \cup \mathrm{B} \in \mathrm{I}$.(finite additivity)

$\begin{array}{lr}\text { Received: } & \text { July 29, 2016 } \\ \text { Revised: } & \text { September 26, 2016 } \\ \text { Published: } & \text { October 21, 2016 }\end{array}$

(c) 2016 Academic Publications, Ltd. url: www.acadpubl.eu 
Throughout this paper $(\mathrm{X}, \tau)$ will denote topological space. For a subset A of a topological space $(\mathrm{X}, \tau)$. The closure of $\mathrm{A}$ (denoted as $\operatorname{cl}(\mathrm{A})$ ) is defined as the intersection of all closed sets containing $\mathrm{A}$ and the interior of $\mathrm{A}$ (denoted as $\operatorname{int}(\mathrm{A}))$ is defined as the union of all open sets contained in $\mathrm{A}$. Let $\mathrm{A} \subset \mathrm{B} \subset$ X. Jafari [7] introduced the concept Generalized closed set with respect to an Ideal. In this paper, we introduce and study the concept of $\mathrm{g}^{*}$-closed sets with respect to an ideal, which is the extension of the concept of Ig-closed sets.

\section{Preliminaries}

Definition 2.1. A subset of a topological space $(\mathrm{X}, \tau)$ is called a generalized closed set (briefly g-closed) if $\mathrm{cl}(\mathrm{A}) \subseteq \mathrm{U}$ whenever $\mathrm{A} \subseteq \mathrm{U}$ and $\mathrm{U}$ is open in $(\mathrm{X}, \tau)$.

Definition 2.2. Let $(\mathrm{X}, \tau)$ be a topological space and $\mathrm{A}$ is a subset of $\mathrm{X}$, the generalized closure operator (briefly $c l^{*}$ )[1] is defined by the intersection of all g-closed sets containing A. The interior operator (briefly int ${ }^{*}$ ) is defined by union of all g-open sets contained in A.

Definition 2.3. A subset of a topological space $(\mathrm{X}, \tau)$ is called a strongly generalized closed set (briefly $g^{*}$-closed) if $\operatorname{cl}(\mathrm{A}) \subseteq \mathrm{U}$ whenever $\mathrm{A} \subseteq \mathrm{U}$ where $\mathrm{U}$ is g-open in $(\mathrm{X}, \tau)$.

Definition 2.4. Let $(\mathrm{X}, \tau)$ be a topological space and I be a ideal on $\mathrm{X}$. A subset $\mathrm{A}$ subset of $\mathrm{X}$ is said to be generalized closed with respect to an ideal (briefly Ig-closed) [7] if and only if $\mathrm{cl}(\mathrm{A})-\mathrm{B} \in \mathrm{I}$ whenever $\mathrm{A} \subset \mathrm{B}$ and $\mathrm{B}$ is g-open.

\section{Strong form of $I g^{*}$ closed sets}

Definition 3.1. Let $(\mathrm{X}, \tau)$ be a topological space and I be a ideal on X. A subset $\mathrm{A}$ subset of $\mathrm{X}$ is said to be strongly g-closed with respect to an ideal (briefly $I g^{*}$-closed) if and only if $c l^{*}(A)-B \in \mathrm{I}$ whenever $\mathrm{A} \subset \mathrm{B}$ and $\mathrm{B}$ is g-open.

Remark 3.2. Every g-closed set is $I g^{*}$-closed,but the converse need not be true.

Example 3.3. Let $\mathrm{X}=\{\mathrm{a}, \mathrm{b}, \mathrm{c}\}$ with topology $\tau=\{\emptyset,\{a\}, X\}$ and $\mathrm{I}=$ $\{\emptyset,\{b\},\{c\},\{b, c\}\}$ clearly the set $\{a\}$ is $I g^{*}$-closed but not g-closed in $(\mathrm{X}, \tau)$. 
Theorem 3.4. A set $A$ is $I g^{*}$-closed in $(X, \tau)$ if and only if $F \subset c l^{*}(A)-A$ and $F$ is g-closed in $X$ implies $F \in I$.

Proof. Assume that $\mathrm{A}$ is $I g^{*}$-closed. Let $\mathrm{F} \subset c l^{*}(A)$-A. Suppose $\mathrm{F}$ is g-closed. Then, A $\subset \mathrm{X}-\mathrm{F}$.By assumption, $c l^{*}(A)-(\mathrm{X}-\mathrm{F}) \in \mathrm{I}$.

Conversely, assume that $\mathrm{F} \subset c l^{*}(A)-\mathrm{A}$ and $\mathrm{F}$ is g-closed in $\mathrm{X}$ implies that $\mathrm{F}$ $\in \mathrm{I}$. Suppose $\mathrm{A} \subset \mathrm{U}$ and $\mathrm{U}$ is g-open. Then $c l^{*}(A)-\mathrm{U}=c l^{*}(A) \cap(\mathrm{X}-\mathrm{U})$ is a g-closed set in $\mathrm{X}$, that is contained in $c l^{*}(A)-A$.By assumption, $c l^{*}(A)-\mathrm{U}$ $\in \mathrm{I}$. This implies that $\mathrm{A}$ is $I g^{*}$-closed.

Theorem 3.5. If $A$ and $B$ are $I g^{*}$-closed sets of $(X, \tau)$ then their union $A \cup B$ is also $I g^{*}$-closed.

Remark 3.6. The intersection of $I g^{*}$-closed sets need not be an $I g^{*}$ closed.

Example 3.7. Let $\mathrm{X}=\{\mathrm{a}, \mathrm{b}, \mathrm{c}\}$ with topology $\tau=\{\emptyset,\{b\},\{b, c\}, X\}$.If $\mathrm{A}$ $=\{\mathrm{b}, \mathrm{c}\}, \mathrm{B}=\{\mathrm{a}, \mathrm{b}\}$ and $\mathrm{I}=\{\emptyset,\{a\},\{c\},\{a, c\}\}$ then $\mathrm{A}$ and $\mathrm{B}$ are $I g^{*}$-closed but their intersection $\mathrm{A} \cap \mathrm{B}=\{\mathrm{b}\}$ is not $I g^{*}$-closed.

Theorem 3.8. If $A$ is $I g^{*}$-closed and $A \subset B \subset c l^{*}(A)$ and in $(X, \tau)$, then $B$ is $I g^{*}$-closed in $(X, \tau)$.

Proof. Suppose $\mathrm{A}$ is $I g^{*}$-closed and $\mathrm{A} \subset \mathrm{B} \subset c l^{*}(A)$ in $(\mathrm{X}, \tau)$. Suppose $\mathrm{B}$ $\subset \mathrm{U}$ and $\mathrm{U}$ is g-open. Then $\mathrm{A} \subset \mathrm{U}$. Since $\mathrm{A}$ is $I g^{*}$-closed, we have $c l^{*}(A)$-U $\in \mathrm{I}$. $\mathrm{B} \subset c l^{*}(A)$. This implies that $c l^{*}(B)-\mathrm{U} \subset c l^{*}(A)-\mathrm{U} \in$ I.Hence $\mathrm{B}$ is $I g^{*}$-closed in $(\mathrm{X}, \tau)$.

Theorem 3.9. Let $A \subset Y \subset X$ and suppose that $A$ is $I g^{*}$-closed in $(X, \tau) \cdot A$ is $I g^{*}$-closed relative to the subspace $Y$ of $X$, with respect to the ideal $I_{\mathrm{y}}=\{F \subset Y: F \in I\}$.

Proof. Suppose A $\subset \mathrm{U} \cap \mathrm{Y}$ and $\mathrm{U}$ is g-open in $(\mathrm{X}, \tau)$ then $\mathrm{A} \subset \mathrm{U}$.Since A is $I g^{*}$-closed in $(\mathrm{X}, \tau)$ we have $c l^{*}(A)-\mathrm{U} \in \mathrm{I}$. Now $\left(c l^{*}(A) \cap \mathrm{U}\right)-(\mathrm{U} \cap \mathrm{Y})$ $=\left(c l^{*}(A) \cap \mathrm{Y}\right) \in \mathrm{I}$,whenever $\mathrm{A} \subset \mathrm{U} \cap \mathrm{Y}$ and $\mathrm{U}$ is g-open. Hence then $\mathrm{A} \subset$ $\mathrm{U}$ and $\mathrm{B} \subset \mathrm{U}$. By definition $\mathrm{n}$ of $I g^{*}$-closed $c l^{*}(A)-\mathrm{U} \in \mathrm{I}$ and $c l^{*}(B)-\mathrm{U} \in \mathrm{I}$. Hence $\mathrm{A}$ is $I g^{*}$-closed relative to the subspace $\mathrm{Y}$.

Theorem 3.10. Let $A$ be an $I g^{*}$-closed and $F$ be a g-closed set in $(X, \tau)$, then $A \cap F$ is an $I g^{*}$-closed in $(X, \tau)$.

Proof. Let $\mathrm{A} \cap \mathrm{F} \subset \mathrm{U}$ and $\mathrm{U}$ is g-open. Then $\mathrm{A} \subset \mathrm{U} \cup(\mathrm{X}-\mathrm{F})$. Since $\mathrm{A}$ is $I g^{*}$-closed, we have $c l^{*}(A)-(\mathrm{U} \cup(\mathrm{X}-\mathrm{F})) \in \mathrm{I}$. Now $c l^{*}(A \cap F)-\mathrm{U} \subset c l^{*}(A \cap F)$ - $(\mathrm{X}-\mathrm{F}) \subset c l^{*}(A)-(\mathrm{U} \cup(\mathrm{X}-\mathrm{F})) \in \mathrm{I}$. Hence $\mathrm{A} \cap \mathrm{F}$ is an $I g^{*}$-closed in $(\mathrm{X}, \tau)$. 


\section{Stronger form of $I g^{*}$ - open sets}

Definition 4.1. Let $(\mathrm{X}, \tau)$ be a topological space and I be an ideal on X. A subset of $\mathrm{A}$ of $\mathrm{X}$ is said to be strongly g-open with respect to an ideal (briefly $I g^{*}$ - open) if and only if X-A is $I g^{*}$-closed.

Theorem 4.2. A set $A$ in $I g^{*}$-closed in $(X, \tau)$ if and only if $F-U \subset$ int $^{*}(A)$ for some $U \in I$ whenever $F \subset A$ and $F$ is g-closed.

Proof. Assume that $\mathrm{A}$ is $I g^{*}$ - open. Let $\mathrm{F} \subset c l^{*}(A)$ - A.Suppose $\mathrm{F}$ is g-closed. Then, X-A $\subset \mathrm{X}-\mathrm{F}$.By our assumption, $c l^{*}(A)-(\mathrm{X}-\mathrm{A}) \subset(\mathrm{X}-\mathrm{F}) \cup \mathrm{U}$ for some $\mathrm{U} \in \mathrm{I}$. This implies $\mathrm{X}-(\mathrm{X}-\mathrm{F}) \cup \mathrm{U} \subset \mathrm{X}-c l^{*}(X-A)$. Conversely,assume that $\mathrm{F} \subset \mathrm{A}$ and $\mathrm{F}$ is g-closed in $\mathrm{X}$ implies $\mathrm{F}-\mathrm{U} \subset$ int $^{*}(A)$ for some $\mathrm{U} \in \mathrm{I}$, whenever $\mathrm{F} \subset \mathrm{A}$ and $\mathrm{F}$ is g-closed. Consider an g-open set $\mathrm{G}$ such that $\mathrm{X}-\mathrm{A}$ $\subset \mathrm{G}$. Then $\mathrm{X}-\mathrm{G} \subset \mathrm{A}$. By our assumption, $(\mathrm{X}-\mathrm{G})-\mathrm{U} \subset i n t^{*}(\mathrm{~A})=\mathrm{X}-c l^{*}(X)$ $-\mathrm{A}$. This gives that $(\mathrm{X}-(\mathrm{G} \cup \mathrm{V})) \subset \mathrm{X}-c l^{*}(X-A) \subset \mathrm{G} \cup \mathrm{U}$, for some $\mathrm{U} \in \mathrm{I}$. This shows that $c l^{*}(X-A)-\mathrm{G} \in \mathrm{I}$. Hence $\mathrm{X}-\mathrm{A}$ is $I g^{*}$-closed.

Theorem 4.3. If $A$ and $B$ are separated $I g^{*}$ - open of $(X, \tau)$ then their union $A \cup B$ is also $I g^{*}$ - open.

Proof. Suppose A and B are separated $I g^{*}$ - open of $(\mathrm{X}, \tau) \mathrm{F}$ be a g-closed subset of $\mathrm{A} \cup \mathrm{B}$.Then $\mathrm{F} \cap c l^{*}(A) \subset \mathrm{A}$ and $\mathrm{F} \cap c l^{*}(B) \subset \mathrm{B}$.By assumption, $(\mathrm{F} \cap$ $\left.c l^{*}(A)\right)-U_{1} \subset i n t^{*}(A)$ and $\left(\mathrm{F} \cap c l^{*}(B)\right)-U_{2} \subset i n t^{*}(B)$, for some $U_{1}, U_{2} \in$ $\mathrm{I}$.This means $\mathrm{F} \cap c l^{*}(A)-i n t^{*}(A) \in \mathrm{I}$ and $\mathrm{F} \cap c l^{*}(B)$ - $i n t^{*}(B) \in \mathrm{I}$.Hence $\mathrm{F} \cap$ $c l^{*}(A) \cup c l^{*}(B)-i n t^{*}(A) \cup i n t^{*}(B) \in \mathrm{I}$ and we have $\left.\mathrm{F}-i n t^{*}(A) \cup B\right)\left(c l^{*}(B)\right.$ $\subset \mathrm{B})$. By definition $\mathrm{n} I g^{*}$-closed, $c l^{*}(A)-\mathrm{U} \in \mathrm{I}$ and $c l^{*}(B)-\mathrm{U} \in \mathrm{I}$.Hence $c l^{*}(A \cup B)-\mathrm{U}=\left(c l^{*}(A)-\mathrm{U}\right) \cup\left(c l^{*}(B)-\mathrm{U}\right) \in \mathrm{I}$.Therefore, $\mathrm{A} \cup \mathrm{B}$ is $I g^{*}$ open.

Corollory 4.4. If A and $\mathrm{B}$ are $I g^{*}$-closed sets and suppose $\mathrm{X}$-A and $\mathrm{X}-\mathrm{B}$ are separated in $(\mathrm{X}, \tau)$.Then their intersection $\mathrm{A} \cap \mathrm{B}$ is $I g^{*}$-closed.

Corollory 4.5. If $\mathrm{A}$ and $\mathrm{B}$ are $I g^{*}$-open sets in $(\mathrm{X}, \tau)$. Then $\mathrm{A} \cap \mathrm{B}$ is $I g^{*}$-open.

Theorem 4.6. If $A$ is $I g^{*}$-closed and $A \subset B \subset X$ is $I g^{*}$-open relative to $B$ is $I g^{*}$-open relative to $X$, then $A$ is $I g^{*}$-open relative to $X$.

Proof. Suppose A $\subset \mathrm{B} \subset \mathrm{X}, \mathrm{A}$ is $I g^{*}$-closed and in $(\mathrm{X}, \tau)$. Suppose A is $I g^{*}$-open relative to $\mathrm{B}$ and $\mathrm{B}$ is $I g^{*}$-open relative to $\mathrm{X}$. Suppose $\mathrm{F} \subset \mathrm{A}$ and $\mathrm{F}$ is g-closed. Since $\mathrm{A}$ is $I g^{*}$-open relative to $\mathrm{B}$, by theorem $4.2, \mathrm{~F}-\mathrm{U} \subset \operatorname{int}^{*}(A)$ for some $\mathrm{U} \in \mathrm{I}$, whenever $\mathrm{F} \subset \mathrm{A}$ and $\mathrm{F}$ is g-closed.Consider an g-open set $\mathrm{G}$ 
such that $\mathrm{X}-\mathrm{A} \subset \mathrm{G}$. Then $\mathrm{X}-\mathrm{G} \subset \mathrm{A}$. By our assumption, $(\mathrm{X}-\mathrm{G})-\mathrm{U} \subset \operatorname{int}^{*}(A)$ $=\mathrm{X}-c l^{*}(X-A)$. This gives that $(\mathrm{X}-(\mathrm{G} \cup \mathrm{V})) \subset \mathrm{X}-c l^{*}(X-A)$. Then $c l^{*}(X-A) \subset \mathrm{G} \cup \mathrm{U}$,for some $\mathrm{U} \in \mathrm{I}$. This shows that $c l^{*}(X-A)-\mathrm{G} \in \mathrm{I}$. Hence $\mathrm{X}-\mathrm{A}$ is $I g^{*}$-closed.

Now $\mathrm{F}-\mathrm{U} \subset \operatorname{int}^{*}(A)$ for some $\mathrm{U} \in \mathrm{I}$, whenever $\mathrm{F} \subset \mathrm{A}$ and $\mathrm{F}$ is g-closed. Consider an g-open set $\mathrm{G}$ such that $\mathrm{X}-\mathrm{A} \subset \mathrm{G}$. Then $\mathrm{X}-\mathrm{G} \subset \mathrm{A}$.

$\mathrm{F}-\left(U_{1} \cup U_{2}\right)=\left(\mathrm{F}-U_{1}\right) \cap\left(\mathrm{F}-U_{2}\right) \subset \mathrm{G} \cap G_{2} \subset G_{1} \cap \mathrm{G} \subset$ A. This implies that F-( $\left.U_{1} \cap U_{2}\right) \subset \operatorname{int}^{*}(A)$, for some $\left(U_{1} \cap U_{2}\right) \in \mathrm{I}$ and hence $\mathrm{A}$ is $I g^{*}$-open relative to $\mathrm{X}$.

Theorem 4.7. Let $\operatorname{int}^{*}(A) \subset B \subset A$ and suppose $A$ is $I g^{*}$-open in $(X, \tau), A$ is $I g^{*}$-open in $X$.

Proof. Suppose $i n t^{*}(A) \subset \mathrm{B} \subset \mathrm{A}$ and $\mathrm{A}$ is $I g^{*}$-open. Then $\mathrm{X}-\mathrm{A}-\mathrm{B} \subset \mathrm{X}$ $\mathrm{B} \subset c l^{*}(X-A)$ and $\mathrm{X}-\mathrm{A}$ is $I g^{*}$-closed in $(\mathrm{X}, \tau)$, theorem $3.8, \mathrm{X}$-A is $I g^{*}$-closed and hence $\mathrm{A}$ is $I g^{*}$-open.

Theorem 4.8. A set $A$ is $I g^{*}$-closed in $(X, \tau)$, if and only if $c l^{*}(A)-A$ is $I g^{*}$-open.

Proof. Necessity: Suppose $\mathrm{F} \subset c l^{*}(A)$-A and $\mathrm{F}$ be g-closed. Then $\mathrm{F} \in \mathrm{I}$. This implies that $\mathrm{F}-\mathrm{U}=\emptyset$ for some $\mathrm{U} \in \mathrm{I}$. Clearly, F-U $\subset i n t^{*}\left(c l^{*}(A)-A\right)$. By theorem $4.2 c l^{*}(A)-A$ is $I g^{*}$-open.

Sufficiency: Suppose $\mathrm{A} \subset \mathrm{G}$ and $\mathrm{G}$ is open in $\mathrm{X}$. Let $\mathrm{A} \cap \mathrm{F} \subset \mathrm{U}$ and $\mathrm{U}$ is g-open. Then $\mathrm{A} \subset \mathrm{U} \cup(\mathrm{X}-\mathrm{F})$.Since $\mathrm{A}$ is $I g^{*}$-closed, we have $c l^{*}(A)-(\mathrm{U} \cup$ $(\mathrm{X}-\mathrm{F})) \in \mathrm{I}$. Now $c l^{*}(A \cap F) \subset c l^{*}(A \cap F)-(\mathrm{X}-\mathrm{F})$.Therfore, $c l^{*}(A \cap F)-\mathrm{U} \subset$ $c l^{*}(A \cap F)-(\mathrm{X}-\mathrm{F}) \subset c l^{*}(A)-(\mathrm{U} \cup(\mathrm{X}-\mathrm{F})) \in \mathrm{I}$. Hence $\mathrm{A} \cap \mathrm{F}$ is $I g^{*}$-closed in $(\mathrm{X}, \tau)$. Thus $\mathrm{A}$ is $I g^{*}$-closed.

\section{References}

[1] W.Dunham, A new closure operator for non-T1 topologies, Kyunpook Math.,J.22(1982),55-60.

[2] T.R.Hamlett and D.Jankovik, Compactness with respect to an ideal, Boll. Un.Mat.Ita.,(7),4-B, (1990),849-861..

[3] T.R. Hamlett and D.Jankovik, Ideals in topological spaces and the set operator, Boll. Un.Mat.Ita.,(7),4-B, (1990),863-874..

[4] T.R. Hamlett and D.Jankovik, Ideals in General topology and Applications (Middletown,CT, 1988), Lecture notes in Pure and Appl.Math.Dekker, New York,(1990),115125, 
[5] ]T.R. Hamlett and D.Jankovik, Compatible extensions of Ideals, Boll. Un.Mat.Ita.,7,(1992),453-465.

[6] D.Jankovik and T.R. Hamlett, New topologies from old via ideals, Amer. Math. Month., 97,(1990),295-310.

[7] S. Jafari, N. Rajesh Generalized Closed Sets with Respect to an Ideal European Journal of Pure and Applied Mathematics vol.4, No. 2,(2011),147-151

[8] K. Kuratowski, Topologies I, Warszawa, 1933.

[9] N. Levine, Generalized closed sets in topology, Rend. Circ. Mat. Palermo,19(2),(1970), 89-96.

[10] R. L. Newcomb, Topologies which are compact modulo an ideal, Ph.D. Dissertation, Univ.Cal.at Santa Barbara,(1967).

[11] A. Pushpalatha and K.Anitha, g*s-closed sets in Topological Spaces Int. J. Contemp. Math. Sciences, Vol. 6, 2011, no. 19,917-219.

[12] A. Pushpalatha, S.Eswaran and P.Rajarubi, $\tau^{*}$ - Generalized Closed Sets in Topological Spaces, Proceedings on the World Congress on Engineering 2009 Vol II, WCE 2009, July 1-3, 2009.London, U.K.

[13] D. V. Rancin, Compactness modulo an ideal, Soviet Math. Dokl., 13,(1972), 193-197.

[14] P. Samuels, A topology from a given topology and ideal, J. London Math. Soc. (2)(10),(1975), 409-416. 